\title{
Personality predicts perceived availability of social support and satisfaction with social support in women with early stage breast cancer
}

\author{
Brenda L. Den Oudsten • Guus L. Van Heck • \\ Alida F. W. Van der Steeg • Jan A. Roukema • \\ Jolanda De Vries
}

Received: 18 November 2008 / Accepted: 27 July 2009/Published online: 16 August 2009

(C) Springer-Verlag 2009

\begin{abstract}
Goals of work This study examines the relationships between personality, on the one hand, and perceived availability of social support (PASS) and satisfaction with received social support (SRSS), on the other hand, in women with early stage breast cancer (BC). In addition, this study examined whether a stressful event (i.e., diagnosis) is associated with quality of life (QOL), when controlling for PASS and SRSS.

Patients and method Women were assessed on PASS and SRSS (World Health Organization QOL assessment instrument-100) before diagnosis (time 1) and 1 (time 2), 3 (time 3), 6 (time 4), 12 (time 5), and 24 months (time 6)
\end{abstract}

B. L. Den Oudsten $(\bowtie) \cdot$ G. L. Van Heck · J. A. Roukema

J. De Vries

Department of Medical Psychology, CoRPS, Center of Research on Psychology in Somatic Diseases, Tilburg University,

P.O. Box 90153, 5000 LE Tilburg, The Netherlands

e-mail: b.1.denoudsten@uvt.nl

URL: http://www.tilburguniversity.nl/corps

G. L. Van Heck

Scientific Centre for Transformation in Care and Welfare (TRANZO), Tilburg University,

Tilburg, The Netherlands

\section{A. F. W. Van der Steeg}

Pediatric Surgical Center of Amsterdam,

Emma Children's Hospital AMC and VU Medical Centre,

Amsterdam, The Netherlands

\section{J. A. Roukema}

Department of Surgery, St. Elisabeth Hospital,

Tilburg, The Netherlands

J. De Vries

Department of Medical Psychology, St. Elisabeth Hospital,

Tilburg, The Netherlands after surgical treatment. Personality (neuroticism extraversion openness five-factor inventory and state trait anxiety inventory-trait scale) and fatigue (fatigue assessment scale) were assessed at time 1 .

Main results Agreeableness and fatigue predicted PASS and SRSS at time 5 and time 6 . Trait anxiety had a negative effect on SRSS $(\beta=-0.22, p<.05)$. In addition, having a job was negatively associated with SRSS (time $6, \beta=-0.28, p<.05$ ). Across time, women reported a decrease in PASS and SRSS. Path models, used to test whether PASS and/or SRSS functioned as mediators of the link between diagnosis and QOL, reached adequate fit.

Conclusions Besides factors, like fatigue and having a job, personality factors substantially influence the way women with early stage BC perceive social support. Knowledge about these underlying mechanisms of social support is useful for the development of tailor-made interventions. Professionals should be aware of the importance of social support. They should check whether patients have sufficient significant others in their social environment and be sensitive to potential discrepancies patients might experience between availability and adequacy of social support.

Keywords Breast neoplasm · Oncology · Personality . Social support

\section{Introduction}

In the Netherlands, over 11,500 women received breast cancer (BC) diagnosis in 2003 [1]. In 2005, there were an estimated number of $119,000 \mathrm{BC}$ patients or survivors in the Netherlands. Due to advances in cancer screening and medical treatment, this number might increase to about 194,000 within 10 years [2]. In spite of these better 
prospects, receiving a $\mathrm{BC}$ diagnosis is still very stressful. For instance, $\mathrm{BC}$ patients have a high risk of developing mood disorders [3]. Therefore, social support from a partner, family, and/or friends is of the utmost importance for women with BC [4].

Despite a growing interest in social support, a precise definition is currently lacking. In general, there are two broad ideas: social support concerns (1) the support that is actually received (i.e., structural support and functional support) or (2) the individual's subjective appraisal of the social support (perceived social support). Structural support refers to the amount of persons or the amount of contact an individual has within the social environment, while functional support is reflecting the types of support the persons within the social network provide (e.g., providing emotional support or practical assistance) [5]. Perceived social support can be divided into the perception that social support is available when needed (perceived availability of social support (PASS)) [5] and the satisfaction with received social support (SRSS). This approach is used in the current study.

Several studies have examined perceived social support in cancer. For instance, Hann et al. [6] reported that greater perceived adequacy of social support among cancer patients was negatively related to depression. With regard to the relationship between perceived social support and survival, findings are rather inconclusive. Whereas some studies [7-9] found a positive relationship between perceived social support and survival, others did not [10]. Social support is also associated with quality of life (QOL) in BC patients [11-17]. Socially isolated women reported more problems compared with women who were socially integrated with regard to physical role functioning, vitality, and physical functioning [16]. Thus, social support seems to fulfill an important role in adaptation efforts of cancer patients.

In order to understand the underlying mechanisms of the protective role of perceived social support, it is important to examine its determinants or the factors associated with it. Few studies have tested those determinants longitudinally [18]. Objective determinants, such as network size or the frequency of contact with network members, explained about $30 \%$ of the variance of perceived social support in a non-cancer population [17]. In addition, perceived social support may also be associated with other factors, for instance, personality. Few studies, however, have examined this particular relationship [19]. Research has shown that extraverts report higher scores on satisfaction with the social support they receive compared with introverts [20, 21]. A longitudinal study among alcoholics [22] found that extraversion and neuroticism were indirectly related to perceived social support through their effects on structural support during treatment. Furthermore, it was demonstrated that agreeableness, i.e., the tendency towards interpersonal trust and consideration of others, predicts actual support from others [21]. Recently, Hoth et al. [23] studied agreeableness in persons with chronic kidney disease. Persons high on agreeableness showed a substantial decrease in depressive symptoms across time, while support had little effect for low-scorers. In another study [4], dispositional optimism and perceived social support were substantially related to well-being in women with BC. In addition, women who were not treated yet and scored low on dispositional optimism experienced more cancer-specific distress. Persons high on trait anxiety were inclined to seek more support from others, while they also tended to be dissatisfied with the received social support [24, 25]. Several studies found that network size decreased due to fatigue $[26,27]$ or to the fact that persons were due to their illness less able to provide support to their social network, which caused an imbalance between the amount of support given to others and the amount of help received by the network [18]. Presumably, this imbalance had a negative impact on their social network. However, there is still a limited body of knowledge regarding the question whether, in line with a decreasing social network, perceived social support also diminishes across time, since the remaining support providers may give the support patients need.

Therefore, the aim of this prospective longitudinal follow-up study was to examine the relationships between personality and PASS and SRSS in early stage BC patients. In addition, we examined whether PASS and/or SRSS mediates the link between diagnosis and QOL. Based on earlier findings, it was hypothesized that women scoring high on extraversion and agreeableness would experience higher perceived availability and higher scores on satisfaction compared with women scoring low or moderately on these traits. Furthermore, it was expected that high scores on neuroticism and trait anxiety would be negatively associated with PASS and SRSS. Moreover, it was hypothesized that the levels of PASS and SRSS would be high in the period around surgical treatment and then, subsequently, would decline. It was expected that women scoring high on trait anxiety would be less satisfied with their social support at all time points compared to women with low or moderate scores. Finally, it was expected that PASS and SRSS are mediators of the link between diagnosis and QOL.

\section{Patients and methods}

\section{Participants}

Women with a palpable lump in the breast or an abnormality on a screening mammography were referred by their general practitioner to the surgical outpatient clinics of the St. Elisabeth 
Hospital (Tilburg, The Netherlands), the Maasland Hospital (Sittard, The Netherlands; since August 2004), or the Jeroen Bosch Hospital (Den Bosch, The Netherlands; since January 2006). The data were collected from September 2002 until September 2006. Of the 799 eligible women, $604(75.6 \%)$ completed the first set of questionnaires. The main reasons for not participating were the length of the test battery and the amount of stress women experienced at their first visit to the hospital. Of these 604 women, 223 were diagnosed with early stage BC (see Fig. 1). A substantial number of women had benign breast problems (BBP; $n=381$ ). Women who had a history of abnormalities in the breast, benign or malignant, or had a breast tumor that was too large $(>5 \mathrm{~cm})$ for breast conserving therapy were excluded from the study $(n=4)$. In order to participate, the women had to have sufficient knowledge of the Dutch language. The questionnaires were completed before the women visited the surgeon or radiologist, i.e., before the diagnosis, benign or malignant, was known. After the baseline measurement (time 1), women completed questionnaires at 1 (time 2), 3 (time 3), 6 (time 4), 12 (time 5), and 24 months (time 6) after surgical treatment. The reference point was surgical treatment, because otherwise, follow-up measures would interfere with the timing of treatment modalities. Participation in the study was not known to the surgeon in attendance and, therefore, could not effect treatment and clinical follow-up. All participants gave written informed consent.
Measures

Women completed the following questionnaires: World Health Organization QOL assessment instrument-100 (WHOQOL-100; $[28,29]$ ) at all time points. The Center for Epidemiological Studies depression scale (CES-D; [30]), the fatigue assessment scale (FAS; [31]), the neuroticism extraversion openness five-factor inventory (NEO-FFI; [32, 33]), and the state trait anxiety inventory (STAI; [34]) were assessed at time 1.

Social support and general health and overall QOL were measured using the WHOQOL-100 [29] (Dutch version [35]). Each facet is measured with four items with a fivepoint Likert scale. High scores on these facets indicate good QOL. Reliability and validity [35-37] are adequate, and sensitivity [38] of the instrument is high. For instance, Cronbach's alpha for the facet social support exceeds 0.80 [37]. This facet consists of four items: (1) Do you get the kind of support from others that you need? (item 43), (2) To what extent can you count on your friends when you need them? (item 44), (3) How satisfied are you with the support you receive from your family? (item 66), and (4) How satisfied are you with the support you receive from your friends (item 67)? In this study, we calculated two subscores by adding the scores of the first two items in order to measure PASS $(\alpha=0.68)$ and the total scores of the last two items in order to measure SRSS $(\alpha=0.73)$. The time frame of reference is the previous 2 weeks.
Fig. 1 Flow chart for the recruitment of women with breast problems. $B B P$ benign breast problems, $B C$ breast cancer

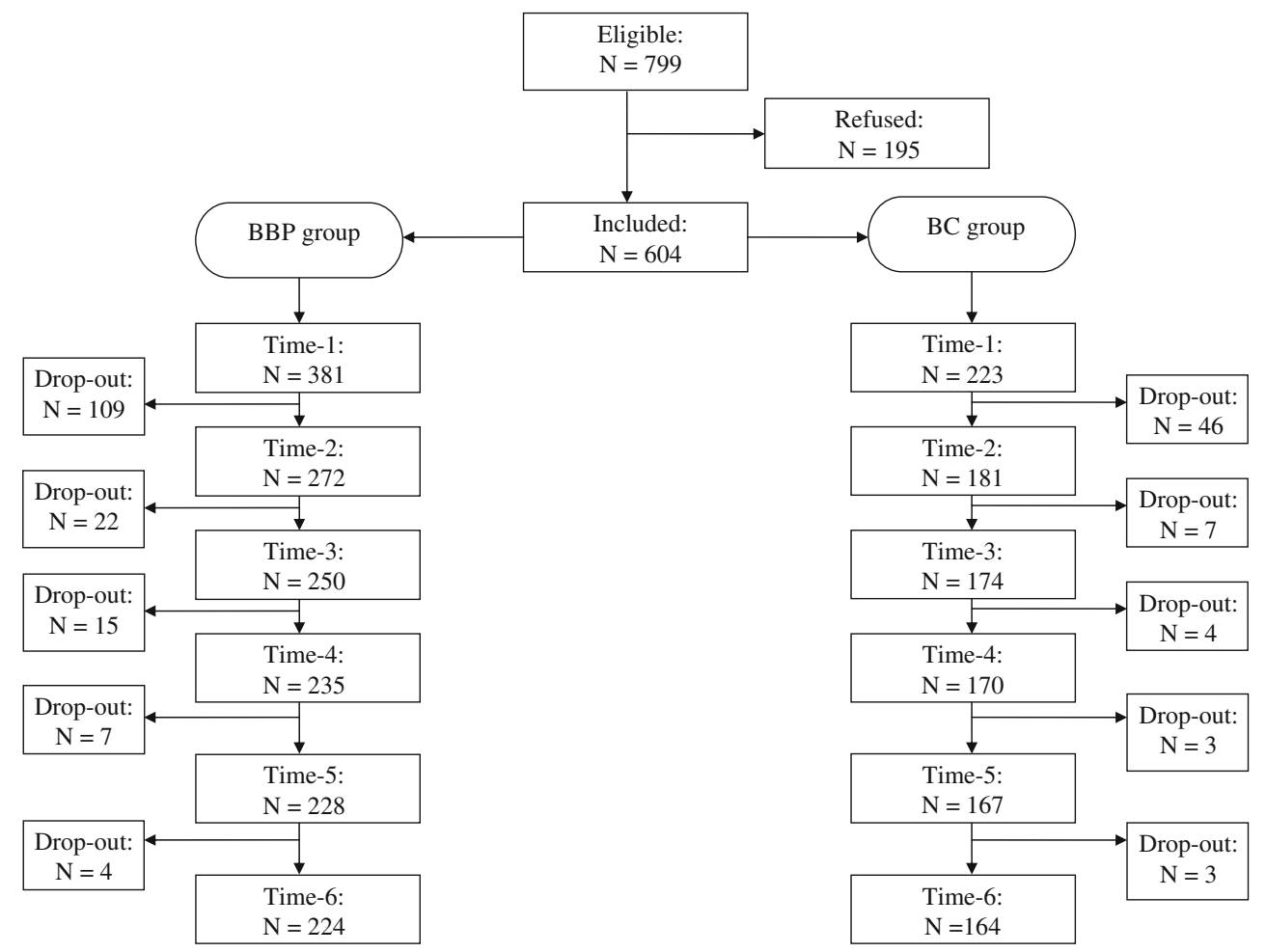


The CES-D [30] is a 20-item self-report scale designed to measure the presence and degree of depressive symptoms over the past week. The rating scale ranges from 0 (seldom or never) to 3 ((almost) always). Scores can range from 0 to 60 . The CES-D has been established as a valid and reliable measure of depressive symptoms in $\mathrm{BC}$ patients [39]. For the Dutch population, reliability and criterion validity are good $[40,41]$.

The FAS [31] is a ten-item questionnaire assessing a unidimensional construct of perceived fatigue and exhaustion. The response scale is a five-point rating scale ranging from 1 (never) to 5 (always). Scores on the FAS range from 10 to 50. The psychometric properties are good [42-44].

Personality was assessed with the NEO-FFI $[32,33]$ and the state trait anxiety inventory (STAI [34], Dutch version by [45]). The NEO-FFI has been translated into Dutch [46]. This self-report questionnaire consists of 60 statements covering five basic dimensions of personality: neuroticism, extraversion, openness to new experiences, agreeableness, and conscientiousness. Each statement is rated on a five-point scale ranging from 1 (strongly disagree) to 5 (strongly agree), resulting in dimension scores between 12 and 60. The psychometrics of the NEO-FFI has been extensively examined. The internal consistency and test-retest reliability, as well as the convergent validity, are acceptable to good [46].

The STAI [34] (Dutch version by [45]) consists of two 20 -item scales for measuring state anxiety and trait anxiety. In this study, the STAI trait scale was used. This scale describes how persons generally feel and refers to their inclination to experience anxiety in stressful times. The STAI has a four-point rating scale ranging from 1 (not at all/almost never) to 4 (very much so/almost always). The Dutch version of the STAI has good reliability and validity [45].

Sociodemographic and clinical variables

Patients were asked to report age, marital status, education, and paid work (yes/no). Clinical variables, for instance, adjuvant therapy, were retrieved from medical files.

\section{Statistical procedure}

Multiple linear regression analyses were performed to identify factors associated with PASS and SRSS at time 5 and time 6 . First, the sets of sociodemographic (age, having children, having a partner, years of education, and having a paid job), clinical (tumor stage, type of surgery, chemotherapy, radiotherapy, and hormone therapy), personality (trait anxiety, neuroticism, extraversion, openness to new experience, agreeableness, and conscientiousness), and psychological characteristics (fatigue and depressive symptoms) were entered separately in the regression analyses. For each group of variables (e.g., sociodemographics), all variables were entered at the same time without making decisions about the order in which variables were put in (i.e., full model). This procedure was employed to minimize the number of independent variables in the final regression analysis preserving statistical power. Subsequently, only those factors that significantly $(p<.05)$ predicted the dependent variables were entered in the final analyses. Multicollinearity was assessed by calculating the variation inflation factor (VIF) for each factor in the regression analyses. A VIF $\geq 2.5$ indicates that multicollinearity is affecting the estimated beta parameter [47]. VIFs did not exceed the cut point. In addition, residual and diagnostic analyses were checked with respect to the assumptions underlying linear regression analyses. Inspection of residuals revealed that the distribution could be considered as fairly normal. General linear model analysis was used to examine PASS and SRSS across time. This was done until time 5 , due to the rather limited sample size at time 6. However, this limited sample size was not a problem in the regression analysis. Partial eta squared (effect size) was derived from the general linear model. An effect size between 0.01 and 0.06 is considered as a small effect, while effect sizes between 0.06 and 0.13 and greater than 0.14 are considered as moderate and strong effect sizes, respectively [48]. Multiple post hoc comparisons were corrected with the Bonferroni method. Path analyses were conducted to test whether PASS and/or SRSS are mediators of the relationship between stress and QOL [49]. In this study, the hypothesized models were tested at each measurement point (time 2 to time 5). In the model, the latent variable "stress" was linked to the diagnosis women had received. Therefore, only in these analyses women with $\mathrm{BC}$ and BBP were used. As outlined above, the PASS and SRSS latent variables were both measured with two observed indicators. In the hypothesized models, stress was specified as the predictor, PASS and SRSS were conceived as mediators, and QOL was specified as the outcome. To evaluate the model, multiple indices of fit were used, including an overall chi-square statistic, the comparative fit index (CFI), and the root mean square error approximation (RMSEA). The models have a satisfactory to good fit when CFI $>0.90$ and RMSEA $<0.06$ [50]. All statistical analyses were performed using the Statistical Package for the Social Sciences (SPSS, Chicago, IL, USA; version 14.0), except for the path analyses. These analyses were performed using Analysis of Moment Structures (version 7.0).

\section{Results}

In total, 799 patients were eligible for this study. Before diagnosis was known, 609 (76.2\%) completed the first set of questionnaires before they visited the surgeon or radiologist. 
Participants were significantly younger compared with nonparticipants $(p=.002)$. Participants and non-participants did not differ on other sociodemographic or clinical characteristics. Figure 1 shows the flow chart of this study. The outcomes regarding the sociodemographic, clinical, and psychological characteristics are presented in Table 1. Women with BBP were younger $[t(1,603)=-6.81, p<.001)$ and more often employed $\left(\chi^{2}=11.46, p=.001\right)$ compared with the $\mathrm{BC}$ group.

The preliminary regression analyses can be found in Table 2 . Trait anxiety $(\beta=-0.22, p=.021)$, agreeableness $(\beta=0.29, p<.0001)$, and fatigue $(\beta=-0.21, p<.008)$ predicted SRSS at time 5. These factors also contributed significantly to the prediction of PASS at time 5, except for trait anxiety. At time 6, agreeableness as well as fatigue predicted PASS and SRSS. In addition, having a job was negatively associated with SRSS $(\beta=-0.28, p<.05$; Table 3$)$.

There was no effect of time on PASS scores for women scoring low or moderately on agreeableness versus highscorers on this trait $(p=.28)$. In addition, no interaction effect was found between time $\times$ agreeableness, showing that agreeableness exerted a stable effect on PASS over time $(p=.73)$. However, low-scorers on agreeableness reported significantly poorer PASS $(p=.001)$ compared to high-scorers (Fig. 2).
In contrast, a significant effect across time was found with regard to SRSS scores and agreeableness (Wilks' lambda $=0.88, F(4,93)=3.16, p=.017$, multivariate partial eta squared $=0.12$; see Fig. 3). No interaction effect was found between time $\times$ agreeableness, showing that agreeableness exerted a stable effect on SRSS over time $(p=.47)$. The mean scores of social support at time 2 were statistically different from the scores obtained at time $4(p=.027)$, indicating a significant decline. Women high on agreeableness had significantly higher scores on SRSS compared with women low or moderately on this trait $(F=9.24, p=.003$, partial eta squared $=0.088$ ).

Concerning trait anxiety, there was also a significant effect across time, indicating that SRSS decreased over time (Wilks' lambda $=0.86, F(4,137)=4.14, p=.004$, multivariate partial eta squared $=0.14$; see Fig. 4 ). The mean scores of SRSS at time 2 were statistically different from the scores obtained at time $4(p=.008)$ and time $5(p=.005)$, indicating a sizeable decline. In addition, women high on trait anxiety had significantly lower scores on SRSS compared with women low or moderately on trait anxiety $(F=34.66, p<.0001$, partial eta squared $=0.25$ ).

Figure 5 presents the path diagrams of the mediational models. These models were used to test whether PASS and/or SRSS functioned as a mediator of the relationship between
Table 1 Demographic, clinical, personality, and psychological characteristics at baseline

For the sociodemographics, percentages are presented between brackets (except for age). For the personality and psychological factors, the means and standard deviations (SD) are presented

MTC modified radical mastectomy, $B C T$ breast conserving therapy

\begin{tabular}{ll}
\hline & BC group $(n=223)$ \\
\hline Sociodemographic factors & \\
Age at diagnosis (mean \pm SD) & $58.7(9.4)$ \\
Living with a partner (yes/no/missing) & $179(80.3) / 37(16.6) / 3(1.3)$ \\
Having children (yes/no/missing) & $191(85.7) / 29(13.0) / 3(1.3)$ \\
Education level $(0-9$ years/10-14 years/>14 years/missing) & $85(38.1) / 95(42.6) / 37(16.6) 2(0.9)$ \\
Paid work (yes/no/missing) & $85(38.1) / 135(60.5) / 1(0.4)$ \\
Disease stage & \\
Stage 0/stage I & $24(10.8) / 93(41.7)$ \\
Stage IIa/stage IIb & $69(30.9) / 35(15.7)$ \\
Undefinable & $2(0.9)$ \\
Type of surgery & \\
BCT/MTC/No surgical treatment & $107(48.0) / 114(51.1) / 2(0.9)$ \\
Adjuvant therapy & \\
Yes/No & $169(75.8) / 54(24.2)$ \\
Personality factors & \\
Neuroticism & $30.2(7.0)$ \\
Extraversion & $41.1(5.5)$ \\
Openness to new experiences & $35.4(6.0)$ \\
Agreeableness & $43.5(4.1)$ \\
Conscientiousness & $45.5(5.4)$ \\
Trait anxiety & $39.4(11.0)$ \\
Depressive symptoms & $14.9(9.5)$ \\
\hline Fatigue & $19.8(9.5)$ \\
\hline & \\
\hline & \\
\hline
\end{tabular}


Table 2 Preliminary regression analyses

\begin{tabular}{|c|c|c|c|c|c|c|c|c|c|}
\hline & \multirow[b]{3}{*}{ Predictors } & \multirow{2}{*}{\multicolumn{2}{|c|}{$\begin{array}{l}\text { PASS } \\
\text { Time } 5\end{array}$}} & \multirow{2}{*}{\multicolumn{2}{|c|}{$\frac{\text { SRSS }}{\text { Time } 5}$}} & \multirow{2}{*}{\multicolumn{2}{|c|}{$\begin{array}{l}\text { PASS } \\
\text { Time } 6\end{array}$}} & \multirow{2}{*}{\multicolumn{2}{|c|}{$\frac{\text { SRSS }}{\text { Time } 6}$}} \\
\hline & & & & & & & & & \\
\hline & & Beta & $p$ value & Beta & $p$ value & Beta & $p$ value & Beta & $p$ value \\
\hline \multirow[t]{5}{*}{ Demographics } & Age & 0.06 & .555 & 0.11 & .328 & -0.17 & .221 & -0.24 & .074 \\
\hline & Children & -0.05 & .571 & -0.06 & .470 & -0.09 & .441 & -0.07 & .528 \\
\hline & Years of education & -0.05 & .588 & -0.06 & .515 & -0.07 & .505 & -0.12 & .291 \\
\hline & Paid job & 0.06 & .582 & 0.05 & .618 & -0.12 & .365 & -0.30 & .025 \\
\hline & Partner & 0.01 & .899 & 0.02 & .874 & 0.06 & .606 & 0.01 & .939 \\
\hline \multirow[t]{5}{*}{ Clinical } & Tumor stage & 0.16 & .124 & 0.09 & .400 & 0.04 & .764 & 0.03 & .838 \\
\hline & Type of surgery & 0.09 & .502 & 0.19 & .151 & 0.10 & .542 & 0.17 & .307 \\
\hline & Chemotherapy & 0.03 & .703 & 0.06 & .481 & 0.12 & .260 & 0.05 & .669 \\
\hline & Radiotherapy & -0.03 & .846 & 0.05 & .676 & 0.07 & .672 & 0.18 & .274 \\
\hline & Hormone therapy & -0.04 & .693 & -0.05 & .656 & 0.07 & .565 & 0.01 & .937 \\
\hline \multirow[t]{6}{*}{ Personality } & Neuroticism & 0.12 & .265 & 0.13 & .211 & 0.02 & .885 & -0.04 & .749 \\
\hline & Extraversion & -0.06 & .500 & -0.09 & .312 & 0.16 & .157 & 0.16 & .137 \\
\hline & Openness & 0.06 & .486 & 0.12 & .132 & -0.06 & .546 & -0.21 & .031 \\
\hline & Agreeableness & 0.31 & .001 & 0.30 & $<.0001$ & 0.34 & .002 & 0.37 & $<.0001$ \\
\hline & Conscientiousness & 0.06 & .509 & 0.12 & .189 & -0.09 & .429 & -0.06 & .549 \\
\hline & Trait anxiety & -0.32 & .001 & -0.40 & $<.0001$ & -0.29 & .015 & -0.31 & .007 \\
\hline \multirow[t]{2}{*}{ Psychological } & Fatigue & -0.39 & $<.0001$ & -0.32 & .002 & -0.37 & .004 & -0.36 & .004 \\
\hline & Depressive symptoms & -0.01 & .941 & -0.16 & .104 & -0.10 & .415 & -0.20 & .099 \\
\hline
\end{tabular}

PASS perceived availability of social support, SRSS satisfaction with received social support

diagnosis and overall QOL at different time points. To reach a better fit, the model required two correlations of two error terms for PASS from time 2 to time 4 ("estimation of QOL" with "stress" and "satisfaction with health" with "stress"). Adding constrains was not necessary for reaching an adequate fit with regard to PASS at time 5. To reach a better fit, the SRSS model required at least two correlations of two error terms (time 2: "estimation of QOL" with "stress", "satisfac- tion with health" with "stress", and "satisfaction with QOL" with "satisfaction with support from family"; time 3: "satisfaction with life in general" with "satisfaction with health", "satisfaction with health" with "stress", "satisfaction with QOL" with "stress", and "diagnosis" with "satisfaction with support from friends"; "time 4: satisfaction with QOL" with "stress" and "satisfaction with health" with "stress"; time 5: "satisfaction with health" with "satisfaction with support
Table 3 Significant predictors of perceived availability of social support and satisfaction with received social support at time 5 and time 6

PASS perceived availability of social support, SRSS satisfaction with received social support

\begin{tabular}{llrrrr}
\hline & Predictors & Beta & $p$ value & Adjusted $R^{2}$ & $F(p$ value $)$ \\
\hline \multirow{2}{*}{ PASS (time 5) } & Trait anxiety & -0.10 & .316 & 0.22 & $13.59(<.0001)$ \\
& Agreeableness & 0.27 & .001 & & \\
& Fatigue & -0.26 & .008 & & $18.35(<.0001)$ \\
SRSS (time 5) & Trait anxiety & -0.22 & .021 & 0.28 & \\
& Agreeableness & 0.29 & $<.0001$ & & \\
& Fatigue & -0.21 & .031 & & \\
PASS (time 6) & Trait anxiety & -0.14 & .236 & 0.28 & \\
& Agreeableness & 0.31 & .001 & & \\
& Fatigue & -0.27 & .024 & & \\
SRSS (time 6) & Trait anxiety & -0.18 & .138 & 0.34 & \\
& Agreeableness & 0.30 & .005 & & \\
& Openness to experience & -0.06 & .550 & & \\
& Paid job & -0.28 & .024 & & \\
& Fatigue & -0.21 & .028 & & \\
& & & &
\end{tabular}




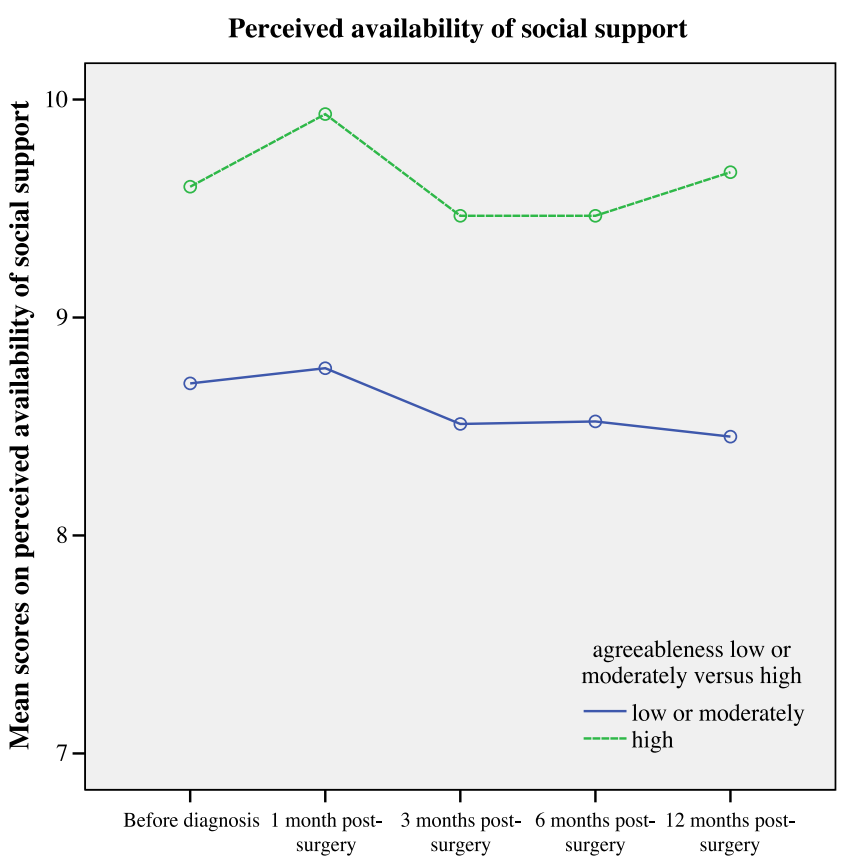

Fig. 2 Perceived availability of social support scores of patients before diagnosis and 1, 3, 6, and 12 months after surgical treatment. Women with early stage breast cancer were divided in two groups, according to their scores on agreeableness (low or moderate versus high)

from family" and "satisfaction with health" with "satisfaction with support from friends"). A summary of the overall goodness-of-fit statistics of the path models and the added error variances are presented in Table 4. These models have a satisfactory fit.

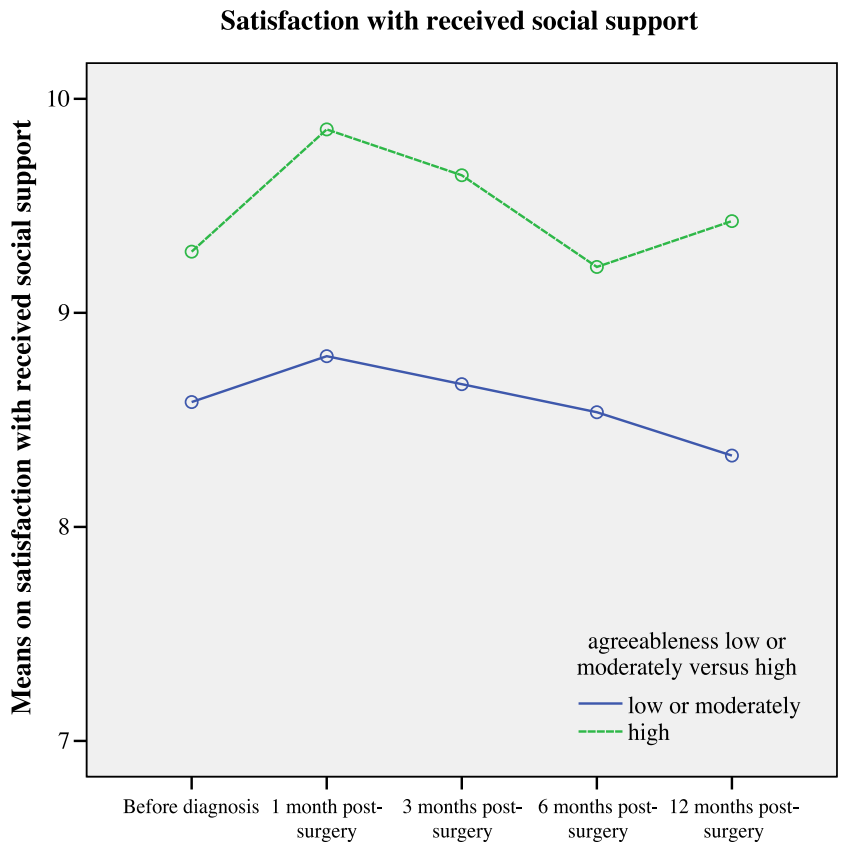

Fig. 3 Satisfaction with received social support scores of patients before diagnosis and 1,3,6, and 12 months after surgical treatment. Women with early stage breast cancer were divided in two groups, according to their scores on agreeableness (low or moderate versus high)

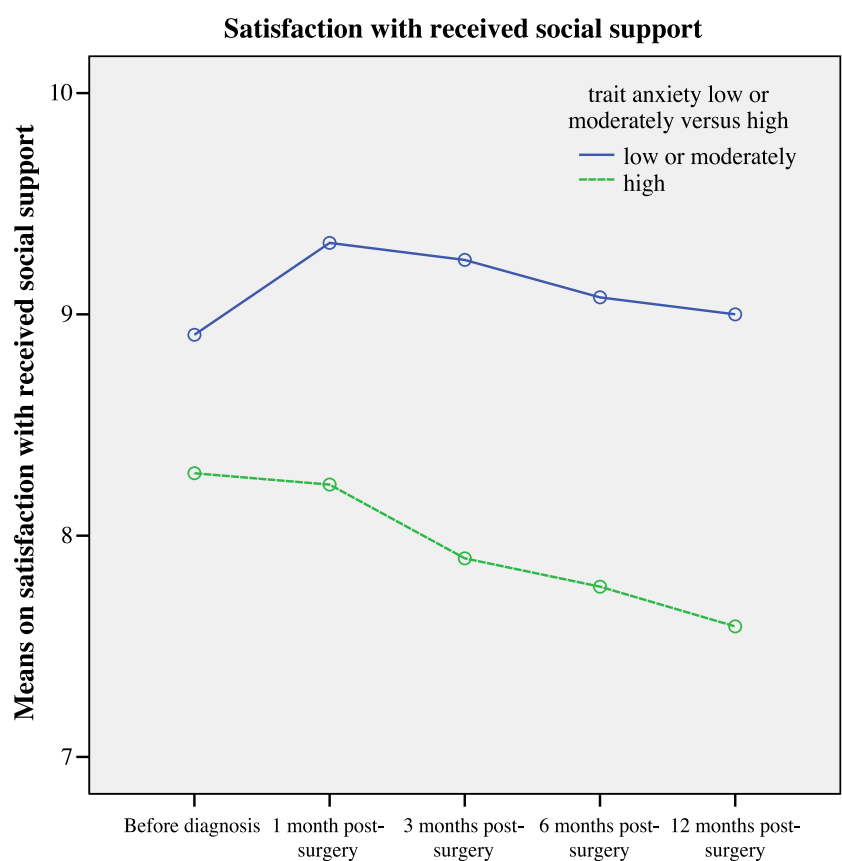

Fig. 4 Satisfaction with received social support scores of patients before diagnosis and 1,3,6, and 12 months after surgical treatment. Women with early stage breast cancer were divided in two groups, according to their scores on trait anxiety (low or moderate versus high)

\section{Discussion}

The aim of this study was to examine the role of personality factors in PASS and SRSS in BC patients. Agreeableness was positively associated with perceived social support at time 5 and time 6 . Several explanations can be given for this finding: (1) persons who are more agreeable may be more strongly motivated to maintain positive relationships with others compared with persons who are less agreeable [51]; (2) high-scorers on agreeableness tend to interpret the

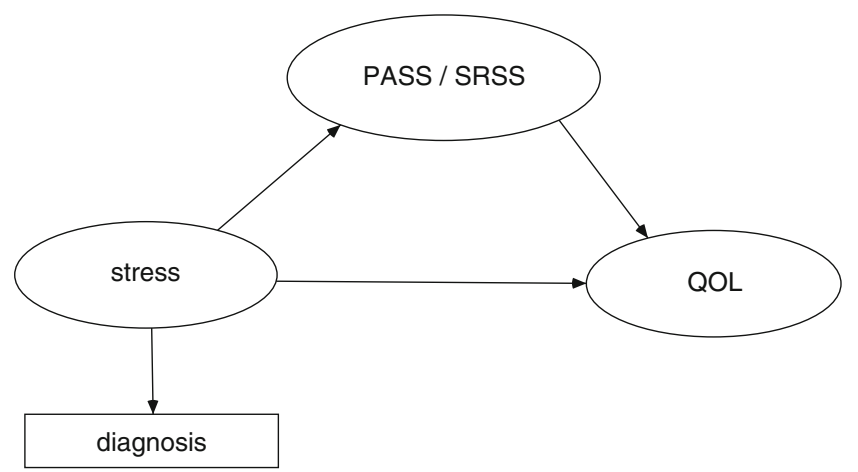

Fig. 5 The path models for perceived availability of social support and satisfaction with received social support as mediator variables in the link between stress at diagnosis of early stage breast cancer and general quality of life across time. Ovals represent latent variables. In the interest of clarity, error terms are not shown. PASS perceived availability of social support, SRSS satisfaction with social support, $Q O L$ quality of life. Stress was measured with the diagnosis women had received 
Table 4 Longitudinal path model statistics

PASS perceived availability of social support, SRSS satisfaction with received social support, $d f$ degrees of freedom, $C F I$ comparative fit index, RMSEA root mean square residuals

\begin{tabular}{lccrrrr}
\hline Model & Chi-square & $p$ value & $d f$ & CFI & RMSEA & Number of constraints \\
\hline PASS, time 1 to time 2 & 8.877 & .449 & 9 & 1.000 & 0.000 & 2 \\
PASS, time 1 to time 3 & 8.877 & .449 & 9 & 1.000 & 0.000 & 2 \\
PASS, time 1 to time 4 & 9.483 & .394 & 9 & 1.000 & 0.000 & 2 \\
PASS, time 1 to time 5 & 11.567 & .481 & 12 & 1.000 & 0.000 & 0 \\
SRSS, time 1 to time 2 & 11.404 & .180 & 8 & 0.997 & 0.038 & 3 \\
SRSS, time 1 to time 3 & 12.132 & .096 & 7 & 0.995 & 0.053 & 4 \\
SRSS, time 1 to time 4 & 6.087 & .731 & 9 & 1.000 & 0.000 & 2 \\
SRSS, time 1 to time 5 & 16.912 & .076 & 10 & 0.992 & 0.054 & 2 \\
\hline
\end{tabular}

behaviors of others more positively and also tend to react more positively upon them [52]. A consequence could be that persons scoring high on agreeableness tend to receive more support from others [53] compared with persons scoring low on this trait. At time 5 and time 6, trait anxiety was negatively associated with perceived social support. Persons scoring high on trait anxiety in general are more anxious. As a result, high-scorers will presumably seek more support from significant others [24]. However, Hobson et al. [25] found that persons scoring high on trait anxiety tend to score lower on perceived social support compared with persons scoring low on trait anxiety. In contrast with persons scoring high on agreeableness, persons scoring high on trait anxiety might interpret the behaviors of others more negatively and also tend to react more negatively upon others. Another explanation may be that highly anxious women are not easily reassured by others. Therefore, they never receive enough social support to feel at ease. At first glance, it seems a paradox that having a job (time 6) is negatively associated with perceived social support, because women who work are usually surrounded by others. An explanation for this finding, however, may be that the environment tends to provide less support or provide support differently due to the fact that women who are working after 2 years of surgical treatment seem to pick up their "normal" life. In this way, women with (former) BC present themselves to others as "doing fine". Although it may seem that women are fully functioning, they perceive the regular check-ups as stressful [54]. Across time, women with early stage BC report a decrease in perceived social support. Women scoring low or moderately on agreeableness or high on trait anxiety tend to score lower on perceived social support compared with women scoring high on agreeableness or low or moderately on trait anxiety across all time points.

Across time, scores of perceived social support significantly declined with respect to trait anxiety and agreeableness. High-scorers on trait anxiety or low-scorers on agreeableness tend to score lower on perceived social support. To what extent, however, social support is actually lower is not clear. To the best of our knowledge, no studies have related personality characteristics to perceived social support longitudinally. However, Courtens et al. studied social support across time and found that the size of the networks as well as the amount of emotional support showed some decrease over time [18].

The path models reached an adequate fit when examining the role of PASS and SRSS as mediating variables of the link between diagnosis and QOL. To the best of our knowledge, no existing studies examined the abovementioned relationship. In fact, few studies have examined relationships between social support and QOL. Recently, Lim and Zebrack [55] found that network diversity indirectly affected QOL through perceived social support. In the past, different hypotheses have been posed to explain the relationship between social support and QOL: the main effects hypothesis and the stress-buffering hypothesis [56]. The main effects hypothesis is referring to a linear relationship between the amount of support and QOL, while the stress-buffering hypothesis states that this relationship is also affected by the level of stress individuals are experiencing $[5,56]$. Studies have been conducted on both models. Recently, Helgeson [5] has made clear that type of support was an important issue. In many studies, emotional support showed the strongest relationship with QOL. However, it should be kept in mind that other types of support, for instance, informational support provided by health professionals or peers is helpful in particular circumstances, i.e., when an individual starts problemoriented coping with stressful situations.

As social support is an aspect of QOL, it seems important to try to increase its level or to improve the fit between the needs of women and the actual type of support provided to women. Potential problems with regard to perceived social support could be improved by, for instance, trying to involve the partner or family in the treatment plan. In this way, significant others are aware of the problems women with early stage $\mathrm{BC}$ are facing during and after the treatment process. Another option is to try to educate women with early stage $\mathrm{BC}$ and their families about the importance of social support, i.e., to teach women to ask for help, when they need support, or to learn how 
they can best discuss their needs, when they are not satisfied. Nevertheless, it is important to keep in mind that personality traits are quite stable. Also, the way persons encounter and perceive social situations is not easily altered. However, while personality traits were significantly associated with social support, they only accounted for a proportion of the variance in perceived social support. Intervention strategies should focus on the more dynamic changeable personality characteristics, like poor coping skills and poor psychosocial resources, instead of the more static dispositional traits [57].

The current study has some limitations. For instance, the study population at time 6 was rather small $(n=92)$. In addition, our study sample was somewhat younger compared with the non-participants. Therefore, we should be careful when interpreting and generalizing the results based on this particular sample. Another limitation is that we only assessed perceived social support. As a consequence, it was not possible to examine whether the same or other sociodemographic and personality factors were related to more quantitative aspects of social support, for instance, network size or frequency of appointments. Information concerning the type of support (i.e., instrumental support and emotional support) women received and needed from significant others was also lacking. Thus, future studies should further examine the role of potential factors which play a role in social support and combine these findings with assessing the needs of women with early stage BC. In this way, screening and treatment can be geared to one another.

In conclusion, personality traits are important determinants of perceived social support. Understanding the underlying mechanisms of perceived social support will be useful in the development of interventions for women with $\mathrm{BC}$.

\section{References}

1. Netherlands Cancer Registry (2005) Most prevalent cancer types [Meest voorkomende kankersoorten]. In: http://www.ikcnet.nl/ page.php?id=1868\&nav_id=114

2. SignaleringscommissieKanker (2004) Cancer in the Netherlands. Trends, prognosis, and implications for care demands [Kanker in Nederland. Trends, prognoses en implicaties voor zorgvraag]. KWF Kankerbestrijding, Amsterdam

3. Burgess C, Cornelius V, Love S, Graham J, Richards M, Ramirez A (2005) Depression and anxiety in women with early breast cancer: five year observational cohort study. BMJ 330(7493):702

4. Friedman LC, Kalidas M, Elledge R, Chang J, Romero C, Husain I et al (2006) Optimism, social support and psychosocial functioning among women with breast cancer. Psycho-oncology 15:595-603

5. Helgeson VS (2003) Social support and quality of life. Qual Life Res 12(Suppl 1):25-31

6. Hann D, Baker F, Denniston M, Gesme D, Reding D, Flynn T et al (2002) The influence of social support on depressive symptoms in cancer patients: age and gender differences. J Psychosom Res 52:279-283
7. Weihs KL, Enright TM, Simmens SJ (2008) Close relationships and emotional processing predict decreased mortality in women with breast cancer: preliminary evidence. Psychosom Med 70:117-124

8. Weihs KL, Simmens SJ, Mizrahi J, Enright TM, Hunt ME, Siegel RS (2005) Dependable social relationships predict overall survival in Stages II and III breast carcinoma patients. J Psychosom Res 59:299-306

9. Kroenke CH, Kubzansky LD, Schernhammer ES, Holmes MD, Kawachi I (2006) Social networks, social support, and survival after breast cancer diagnosis. J Clin Oncol 24(7):1105-1111

10. Cassileth BR, Lusk EJ, Miller DS, Brown LL, Miller C (1985) Psychosocial correlates of survival in advanced malignant disease? N Engl J Med 312:1551-1555

11. Manning-Walsh J (2005) Social support as a mediator between symptom distress and quality of life in women with breast cancer. J Obstet Gynecol Neonatal Nurs 34:482-493

12. Lewis JA, Manne SL, DuHamel KN, Vickburg SM, Bovbjerg DH, Currie V et al (2001) Social support, intrusive thoughts, and quality of life in breast cancer survivors. J Behav Med 24:231245

13. Ogce F, Ozkan S, Baltalarli B (2007) Psychosocial stressors, social support and socio-demographic variables as determinants of quality of life of Turkish breast cancer patients. Asian Pac J Cancer Prev 8:77-82

14. Karnell LH, Christensen AJ, Rosenthal EL, Magnuson JS, Funk GF (2007) Influence of social support on health-related quality of life outcomes in head and neck cancer. Head Neck 29:143-146

15. Sammarco A (2001) Perceived social support, uncertainty, and quality of life of younger breast cancer survivors. Cancer Nurs 24:212-219

16. Michael YL, Berkman LF, Colditz GA, Holmes MD, Kawachi I (2002) Social networks and health-related quality of life in breast cancer survivors: a prospective study. J Psychosom Res 52:285293

17. Cutrona CE (1986) Objective determinants of perceived social support. J Pers Soc Psychol 50(2):349-355

18. Courtens AM, Stevens FC, Crebolder HF, Philipsen H (1996) Longitudinal study on quality of life and social support in cancer patients. Cancer Nurs 19:162-169

19. Roberts S, Wilson R, Fedurek P, Dunbar R (2008) Individual differences and personal social network size and structure. Pers Individ Differ 44:954-964

20. Swickert R, Rosentreter C, Hittner J, Mushrush J (2002) Extraversion, social support, and stress. Pers Individ Differ 32:877-891

21. Bowling N, Beehr T, Swader W (2005) Giving and receiving social support at work: the roles of personality and reciprocity. $\mathrm{J}$ Vocat Behav 67:476-489

22. Russell D, Booth B, Reed D, Laughin P (1997) Personality, social networks, and perceived social support among alcoholics: a structural equation analysis. J Pers 65:649-692

23. Hoth KF, Christensen AJ, Ehlers SL, Raichle KA, Lawton WJ (2007) A longitudinal examination of social support, agreeableness and depressive symptoms in chronic kidney disease. J Behav Med 30:69-76

24. Deisinger J, Cassisi J, Withaker S (2003) Relationships between coping style and PAI profiles in a community sample. J Clin Psychol 59:1315-1323

25. Hobson JA, Slade P, Wrench IJ, Power L (2006) Preoperative anxiety and postoperative satisfaction in women undergoing elective caesarean section. Int J Obstet Anesth 15:18-23

26. Curt GA, Breitbart W, Cella D, Groopman JE, Horning SJ, Itri LM et al (2000) Impact of cancer-related fatigue on the lives of patients: new findings from the Fatigue Coalition. Oncologist 5 (5):353-360 
27. Diaz N, Menjon S, Rolfo C, Garcia-Alonso P, Carulla J, Magro A et al (2008) Patients' perception of cancer-related fatigue: results of a survey to assess the impact on their everyday life. Clin Transl Oncol 10(11):753-757

28. WHOQOL group (1995) The World Health Organization Quality of Life assessment (WHOQOL): position paper from the World Health Organization. Soc Sci Med 41:1403-1409

29. WHOQOL Group (1998) The World Health Organization Quality of Life Assessment (WHOQOL): development and general psychometric properties. Soc Sci Med 46:1569-1585

30. Radloff LS (1977) The CES-D scale: a self-report depression scale for research in the general population. Appl Psychol Meas 1:385401

31. Michielsen HJ, De Vries J, Van Heck GL (2003) Psychometric qualities of a brief self-rated fatigue measure: the fatigue assessment scale. J Psychosom Res 54(4):345-352

32. Costa PT, McCrae RR (1985) The NEO personality inventory manual. Psychological Assessment Resources Inc., Odessa, FL

33. Costa PT, McCrae RR (1992) Revised NEO personality inventory (NEO-PI-R) and NEO five factor inventory (NEO-FFI) professional manual. Psychological Assessment Resources Inc., Odessa, FL

34. Spielberger CD, Gorsuch RL, Lushene RE (1970) STAI manual for the state-trait anxiety inventory. Consulting Psychologists Press, Palo-Alto, CA

35. De Vries J, Van Heck GL (1997) The World Health Organization quality of life assessment instrument (WHOQOL-100): validation study with the Dutch version. Eur J Psychol Assess 13:164-178

36. Power M, Harper A, Bullinger M (1999) The World Health Organization WHOQOL-100: tests of the universality of quality of life in 15 different cultural groups worldwide. Health Psychol 18:495-505

37. Den Oudsten BL, Van Heck GL, Van der Steeg AF, Roukema JA, De Vries J (2009) The WHOQOL-100 has good psychometric properties in breast cancer patients. J Clin Epidemiol 62(2):195205

38. O'Carroll RE, Smith K, Couston M, Cossar JA, Hayes PC (2000) A comparison of the WHOQOL-100 and the WHOQOL-BREF in detecting change in quality of life following liver transplantation. Qual Life Res 9:121-124

39. Hann D, Winter K, Jacobsen P (1999) Measurement of depressive symptoms in cancer patients: evaluation of the Center for Epidemiological Studies depression scale (CES-D). J Psychosom Res 46(5):437-443

40. De Rijk AE, Schreurs KMG, Bensing JM (1999) What is behind "I'm so tired"? Fatigue experiences and their relations to the quality and quantity of external stimulation. J Psychosom Res 47:509-523

41. Beekman AT, Deeg DJ, Van Limbeek J, Braam AW, De Vries MZ, Van Tilburg W (1997) Criterion validity of the Center for Epidemiologic Studies depression scale (CES-D): results from a community-based sample of older subjects in The Netherlands. Psychol Med 27:231-235

42. De Vries J, Michielsen H, Van Heck GL, Drent M (2004) Measuring fatigue in sarcoidosis: the fatigue assessment scale (FAS). Br J Health Psychol 9(Pt 3):279-291

43. Michielsen HJ, De Vries J, Drent M, Peros-Golubicic T (2005) Psychometric qualities of the fatigue assessment scale in Croatian sarcoidosis patients. Sarcoidosis Vasc Diffuse Lung Dis 22 (2):133-138

44. Michielsen H, De Vries J, van Heck GL, Van de Vijver A, Sijtsma K (2004) Examination of the dimensionality of fatigue: the construction of the fatigue assessment scale (FAS). Eur J Psychol Assess 20:39-48

45. Van der Ploeg HM, Defares PB, Spielberger CD (1980) ZBV: a Dutch-language adaptation of the Spielberger state-trait anxiety inventory. Swets \& Zeitlinger, Lisse, The Netherlands

46. Hoekstra H, Ormel J, De Fruyt F (1996) Handleiding NEO persoonlijkheidsvragenlijsten NEO-PI-R en NEO-FFI [Manual NEO personality questionnaires NEO-PI-R and NEO-FFI]. Swets Test Services, Lisse, The Netherlands

47. Stevens J (2002) Applied multivariate statistics for the social sciences Mahwah. Lawrence Erlbaum Associates, NJ

48. Cohen J (1988) Statistical power analysis for the behavioral sciences, vol 2nd. Lawrence Erlbaum, Hillsdale, NJ

49. Preacher KJ, Hayes AF (2004) SPSS and SAS procedures for estimating indirect effects in simple mediation models. Behav Res Meth Instrum Comput 36(4):717-731

50. Hu L, Bentler PM (1999) Cutoff criteria for fit indexes in covariance structure analysis: conventional criteria versus new alternatives. Struct Equ Modeling 6:1-55

51. Jensen-Campbell LA, Graziano WG (2001) Agreeableness as a moderator of interpersonal conflict. J Pers 69:323-361

52. Finch JF, Graziano WG (2001) Predicting depression from temperament, personality, and patterns of social relations. J Pers 69:27-55

53. Branje SJ, Van Lieshout CF, Van Aken MA (2004) Relations between Big Five personality characteristics and perceived support in adolescents' families. J Pers Soc Psychol 86:615-628

54. Ferrell BR, Grant MM, Funk B, Otis-Green S, Garcia N (1997) Quality of life in breast cancer survivors as identified by focus groups. Psycho-oncology 6:13-23

55. Lim JW, Zebrack B (2008) Different pathways in social support and quality of life between Korean American and Korean breast and gynecological cancer survivors. Qual Life Res 17(5):679-689

56. Cohen S, Wills TA (1985) Stress, social support, and the buffering hypothesis. Psychol Bull 98(2):310-357

57. Scheier MF, Helgeson VS, Schulz R, Colvin S, Berga SL, Knapp $\mathrm{J}$ et al (2007) Moderators of interventions designed to enhance physical and psychological functioning among younger women with early-stage breast cancer. J Clin Oncol 25(36):5710-5714 